\title{
Effectiveness of Therapeutic Horseback Riding on Social Skills of Children with Autism Spectrum Disorder in Shiraz, Iran
}

\author{
Hemati Ghorban ${ }^{1}$, Rezaei Dehnavi Sedigheh ${ }^{2}$, Gholami Marzieh ${ }^{1} \&$ Gharghani Yaghoob ${ }^{1}$ \\ ${ }^{1}$ Faculty of Education and Psychology, Special Education Department, Shiraz University, Eram Square, Shiraz, \\ Iran \\ ${ }^{2}$ Psychology and Counseling Department, Payame Noor University, Tehran, Iran \\ Correspondence: Rezaei Dehnavi Sedigheh, Psychology and Counseling Department, Payame Noor University, \\ 19395-4697, Tehran, Iran. E-mail: srezaeidehnavi@pnu.ac.ir
}

Received: April 22, 2013 Accepted: May 23, $2013 \quad$ Online Published: August 14, 2013

doi:10.5539/jel.v2n3p79 URL: http://dx.doi.org/10.5539/jel.v2n3p79

\begin{abstract}
The purpose of this study was to investigate the effect of therapeutic horseback riding on social skills of children with autism spectrum disorder. Participants were 6 children with autism spectrum disorder in a special education center for autistic children in Shiraz, Iran. The hypothesis of the study was that participants would demonstrate significant improvement in social skills following a 4-week horseback riding intervention. Using a One Group Pre and Post Test design, the Stone's social skills Scale was administered to assess the social skills of children with autism spectrum disorder as pretest. Then the subjects participated in a 4-week therapeutic horseback riding program consisting of two 45 minute session of riding per week. After completion of the 4-week intervention the post-test was administered. Paired-samples t-test was utilized to analyze the data. The results indicated that therapeutic horseback riding improves affective understanding and perspective taking, initiating interactions and maintaining interactions significantly. It can be concluded that therapeutic horseback riding has a positive effect on social skills improvement.
\end{abstract}

Keywords: children with autism, social skills, therapeutic horseback riding

\section{Introduction}

Autism spectrum disorder is a neurodevelopmental disorder affecting verbal and nonverbal communication and social interaction significantly and generally appears before 3 years old (Smith et al, 2011). Social deficits are intrinsic to the definition of autism spectrum disorder From Kanner's (1943) original conceptualization to the most recent Diagnostic and Statistical Manual of Mental Disorders (American Psychiatric Association (APA), 2000) (Koach, 2000). Social deficits observed in children with autism spectrum disorder may include: difficulties in understanding the facial expressions of others, initiating social interactions with others, lack of responding to social initiations made by others (Hauck, Fein, Waterhouse, \& Feinstein, 1995) lack of responding to the emotions of others (Sigman, Kasari, Kwon, \& Yirmiya, 1992), deficits in showing directing attention (Stone, Coonrod, \& Ousley, 2000), lack of interest in other children, absence of or limited use of gestures such as pointing, to share enjoyment with others, absence of or limited imitation skills and lack of friendship seeking behavior (Ingersoll, Lewiss, \&Kroman, 2007).

The treatment of social skills deficits remains one of the most challenging areas in meeting the needs of people with autism spectrum disorder. Therefore, it is necessary to plan and accomplish appropriate interventional programs to improve their social skills (Scottone et al, 2006). In this regard, various interventional methods and programs have been developed and applied throughout world. One of these therapeutic methods is "Therapeutic Horseback Riding". A variety of researchers have studied the efficacy of therapeutic horseback riding on the social skills of children with autism spectrum disorder and emphasized its positive results. As an example, Bass et al (2009) have studied the influence of therapeutic horseback riding on the social functioning of children with autism. In their research, 34 children with autism (19 children in an experimental group and 15 in the control group) took part in therapeutic horseback riding for one 60 minute session per week, over a period of 12 weeks. The results indicated that autistic children exposed to therapeutic horseback riding exhibited greater sensory seeking, sensory sensitivity, social motivation, and less inattention, and distractibility behaviors and concluded that therapeutic horseback riding may be a viable therapeutic option in treating children with autism spectrum 
disorder (ASD). Also, King (2007) has studied the effect of therapeutic horseback riding on social behaviors in children with autism. The participants were 5 children with autism who were under the intervention for one 120 minute session over a period of 10 weeks. Therapeutic horseback riding intervention contains sensory activities, assignments and practices when getting on and off the horse that are presented by the horseback riding trainer. The participants were assessed before and after therapeutic horseback riding intervention by their teachers and supervisors. The results showed therapeutic horseback riding improves eye contact, verbal language, cooperative and social behaviors. Consistent with the above findings, Gabliels et al (2012) studied the impact of therapeutic horseback riding on adaptive behaviors in children and adolescents with autism spectrum disorder. They conducted therapeutic horseback riding on 42, 6-16 years old children with autism spectrum disorder (16 in the control group and 26 in the experimental group) for 10 sessions. The results revealed that therapeutic horseback riding improved adaptive behaviors in people with autism spectrum disorder.

In Iran, it seems there is no published research about the effectiveness of therapeutic horseback riding on social skills in children with autism spectrum disorder. Therefore, this research is an attempt to study the effectiveness of therapeutic horseback riding on the social skills of children with autism spectrum disorder living in Shiraz city, Iran.

\section{Method}

\subsection{Participants}

6 children diagnosed with autism spectrum disorder who participated in the study were recruited from the MehrMihan Autism Center in Shiraz, Iran. All participants met criteria for DSM-IV-TR (American Psychiatric Association, 2000). Demographics characteristics of participants are presented in table1.

Table 1. Participants' characteristics based on age, gender, father's and mother's academic level

\begin{tabular}{lllll}
\hline child & age & gender & $\begin{array}{l}\text { father' s academic } \\
\text { level }\end{array}$ & $\begin{array}{l}\text { mother's } \\
\text { academic level }\end{array}$ \\
\hline 1 & 9 & $\mathrm{~F}$ & undergraduate & undergraduate \\
2 & 8 & $\mathrm{~F}$ & under diploma & undergraduate \\
3 & 12 & $\mathrm{M}$ & under diploma & undergraduate \\
4 & 10 & $\mathrm{~F}$ & under diploma & under diploma \\
5 & 6 & $\mathrm{~F}$ & under diploma & under diploma \\
6 & 6 & $\mathrm{~F}$ & undergraduate & undergraduate \\
\hline
\end{tabular}

As it is observed in table 1, the participants were 5 girls and one boy (average age of 8.5 and standard deviation of 2.35). Moreover, the father's academic level of two children was undergraduate whereas mother's academic level of 4 children was undergraduate and two were under diploma (i.e., they don't have diploma certification). Parents had to consent to pre-testing, 8 sessions of therapeutic horseback riding, and one post testing session. Measurements were given to parents before the intervention sessions were initiated. Post-test assessment took place at the completion of the 8 week intervention.

\section{Instrument}

\subsection{Social Skills Assessment Scale}

The Social Skills Rating Form is a subscale of Triad Social Skills Assessment (TSSA) - Second Edition developed by Stone et al (2003) to assess 6-12 year children with autism spectrum disorder. This instrument was developed originally to address the need for a relatively brief, easy-to-administer tool for evaluating the complex social profiles of children with autism spectrum disorder, identifying strengths and challenges in the social domain, and providing recommendations for intervention planning through individualized goals and specific strategies.

The Social Skills Rating Form contains descriptors of social behaviors in areas that include affective understanding/perspective taking, initiating interactions, responding to interaction and maintaining interactions. The respondent (parent or teacher) rates the child's ability to perform each behavior on a four point scale, ranging from "not very well" to "very well". Stone et al (2003) reported its reliability as 0/92 for parents rating and 0/94 for rating teachers through Cronbach alpha. They also confirmed its content validity. The parents' form 
was used in this study. The construct validity was $0 / 79-0 / 93$ through correlation method between the whole test and its subscales. The reliability for the whole scale was $0 / 86$ by the Cronbach alpha coefficient.

\subsection{Therapeutic Horseback Riding Sessions}

The intervention of therapeutic horseback riding was administered for all the children for two 45-min sessions per week over a one month period. The area of horseback riding was approximately the equivalent size of a football field where the observers' area was separated with a fence and the stable of horses was in the riding area. Two experienced trainers were used and parents and teachers assisted the trainers. The intervention of therapeutic horseback riding was done through these stages:

\subsection{Familiarity Stage}

In this stage, a child with autism spectrum disorder becomes familiar with the horse, in the way that she/he is trained to learn how to sit on the horse appropriately, how to get on and off the horse, all the body organs of the horse are introduced and the child is required to touch its body and name them. When the child was sitting on the horse, the trainer was talking about horse voice and food. It must be noticed that it takes 5 minutes in each session and the purposes are to reinforce communicational and social skills, reinforce senses and the ability to balance.

\subsection{Practices}

In this stage, the child practices how to get on and off the horse, how to get the snaffle bite (A snaffle bit is the most common type of bit used while riding horses. It consists of a bit mouthpiece with a ring on either side and acts with direct pressure) of the horse, move the horse, stop the horse and pet the horse. It is noticeable that the training of this stage was modeled by the riding trainer step by step. It takes 10 minutes and the goals are to reinforce communication and social skills, senses and the ability to balance and the child's mastery of the necessary skills for horseback riding.

\subsection{Riding Skills}

At this stage, the two horses were used for each child to sit on (the saddle was used). The children knew each other. The two children ride simultaneously on separate horses and the trainer get the snaffle bit and move the horse. Then, the child's parents get on the horse with the child and move the horse slowly and increase the speed gradually. It is noticeable that, in this stage, attempts are made to sit the child on the horse appropriately. The child was asked to touch the horse's mane. The child was asked to touch the horse's body with him/her feet. Parents were encouraging their child to look at the people was outside of the horse ride area, waved to them and express his/her emotions. Also they want the child pay attention to another horse that was moving and the other child who was sitting on it. Parents were encouraging their child to look at the other child and waved to him and interpret the emotions of other child. Moreover, all the activities carried out by parents, by trainer was also repeated. Actually, the trainer gets on the horse with the child and ride faster than the parents. It takes 15 minutes and the goals were to reinforce communication and social skills, senses and the ability to balance.

\subsection{End of Riding Stage}

In the last stage, children are trained to clean and care for the horse. The trainer does these activities step by step both verbally and practically and the child repeats them. Actually during the last part of the program, participants took part in grooming activities. Children learned how to properly groom and care for their horse by learning to identify grooming tools (curry comb, hoof pick, body brush, mane/tail comb, face brush, etc.) and bathing tools (sponge, water, shampoo, bucket, sweat scraper, etc.). At this stage, the child's verbal and nonverbal communication was reinforced by trainer. It takes 15 minutes.

\section{Results}

Research hypothesis: Horseback riding improves the social skills of children with autism spectrum disorder significantly.

To study this hypothesis, a paired-samples $t$ test was used to analyze the data. The results of total scores in children's' social skills and its subscales are presented in Table 2 . 
Table 2. Paired-samples $t$ test result for comparing pre-test and post-test in the social skills of children with autism spectrum disorder

\begin{tabular}{|c|c|c|c|c|}
\hline subscale & Pre-test scores & Pos-test scores & $\mathbf{t}$ & sig. \\
\hline $\begin{array}{l}\text { Affective } \\
\text { Understanding/ } \\
\text { perspective Taking }\end{array}$ & 15.83 & 18.33 & 4.03 & 0.01 \\
\hline $\begin{array}{l}\text { initiating } \\
\text { interaction }\end{array}$ & 18.50 & 21.33 & 3.78 & 0.01 \\
\hline $\begin{array}{l}\text { Responding to } \\
\text { interaction }\end{array}$ & 12.00 & 14.00 & 1.69 & 0.15 \\
\hline $\begin{array}{l}\text { maintaining } \\
\text { interaction }\end{array}$ & 13.50 & 15.83 & 5.53 & 0.003 \\
\hline $\begin{array}{l}\text { total score of social } \\
\text { skills }\end{array}$ & 56.66 & 64.66 & 3.75 & 0.04 \\
\hline
\end{tabular}

As it is seen in table 2, the total mean scores of social skills in children with autism spectrum disorder in post-test were higher than pre-test. The results of paired-samples $t$ test shows there is a significant difference between total score mean of social skills in children with autism in pre-test and post-test $(t=3.75, \mathrm{df}=5, \mathrm{p}<0.05)$. This suggests that therapeutic horseback riding has a significant effect on social skills of children with autism spectrum disorder.

Also, the results of the social skills subscales in children with autism spectrum disorder reveal that the score mean of affective understanding/perspective taking, initiating interactions and maintaining interactions of children with autism spectrum disorder in post-test was higher than pre-test. The results of paired-samples $t$ test showed there is a significant difference between the score of pre-tests and post-tests $(p<0.05)$. It is considerable that although autistic children's responding to interaction in post-test is higher than pre-test but the results of paired-samples $t$ test show there is a no significant difference between the score mean of autistic children's responding to interaction in pre-test and post-test $(\mathrm{t}=1.69, \mathrm{df}=5, \mathrm{p}<0.15)$. It means that the effect of therapeutic horseback riding on autistic children's responding interaction is not statistically significant. Overall, the findings suggest that therapeutic horseback riding has improved all subscales of social skills.

\section{Discussion and Conclusion}

The purpose of the present research was to study the effect of therapeutic horseback riding on social skills of children with autism spectrum disorder. The research findings revealed that therapeutic horseback riding could significantly improve the social skills of children with autism spectrum disorder. Moreover, the results showed therapeutic horseback riding could significantly improve subscales of affective understanding/perspective taking, initiating interactions, and maintaining interactions in children with autism spectrum disorder. This finding was consistent with Bass et al (2009), King (2007) and Gabriels et al (2012).

To clarify these finding, it can be said therapeutic horseback riding provides multi-sensory stimulation which is useful to improve social, cognitive, relational and motor skills of children with developmental disorders (Bass et al, 2009). In this regard, Britton (1991) has concluded that horseback riding leads to develop social, emotional and physical skills. In the intervention of therapeutic horseback riding, the children with autism spectrum disorder are trained to order the horse verbally, control and direct it. This activity improves verbal language and communicational skills of children with autism spectrum disorder (Gabriels et al, 2012).

Participants learn to follow the trainer's commands in riding which reinforces children's concentration, listening skills, communicational and social interaction (Hamill et al, 2007). Moreover, successful mastery of horseback riding skills improves self-efficacy, self-concept, self-esteem and self-controlling (Macauley \& Gutierrez, 2004) and affects positively on social skills of children with autism spectrum disorder. As a whole, horseback riding leads to improved sensory-motor processing and then leads to more regular sensory-motor experiences and helps autistic individuals to function better in cognitive, physical, affective and social areas (All \& Loving,1999).

Since in therapeutic horseback riding the child is forced to touch the body of the horse and tells its name and she/he is trained to listen to the trainer, repeat the orders verbally and enact them practically, all these activities reinforce the basis of social skills such as active listening, obeying the orders, active cooperation and response 
and leads to improve social skills.

To confirm this clarification, Bass et al (2009) emphasize therapeutic horseback riding is a reinforcing stimulus which improves the motivation and cooperation of children with autism. Of course, Bass et al (2009) believe that an individual's cognitive, emotional and social functioning are affected by cerebellum functioning. The deficit of children with autism's social functioning is attributed to dysfunction of cerebellum and they explain that therapeutic horseback riding improves cerebellum functioning and positively affects the social functioning of children with autism. Keino et al (2009) indicated that therapeutic horseback riding stimulates children with autism's brain through rhythmic and systemized movement of Broca area (its role is in verbal language) and, in the following, helps to develop social skills in children with autism.

Furthermore, in the intervention of therapeutic horseback riding, children are encouraged to disclose their emotions freely and interpret other children's emotion which leads to improve emotional understanding and social skills.

Also, Funahashi \& Carterette (1985) explained children with autism spectrum disorder, through therapeutic horseback riding, learn to disclose their feeling and emotion and reciprocal emotion disclosure has been warmly accepted from parents, riding trainers, academic trainers and those presented in therapeutic horseback riding. These emotional and cognitive changes in children with autism spectrum disorder lead to affective understanding of these children. Keino et al (2009) believe that therapeutic horseback riding improves emotional and cognitive assessment of children with autism spectrum disorder from new stimuli. As a result, these children consider new stimuli not threatening and not dangerous and, thus, they make emotional and cognitive mutual relationship with their parents and others.

In therapeutic horseback riding especially when the horse is trotting, children with autism spectrum disorder start laughing and show their happiness through their gestures. Then they become interested in demonstrating their happy feeling through a brief and incomplete talking and in a more advanced level, through physical activity and words. They are also encouraged to transfer their feeling to their parents and seek positive emotional responses through eye contact with their parents' (Keino et al, 2009) and all these activities lead to improve the social skills of children with autism spectrum disorder.

As a whole, therapeutic horseback riding decreases children with autism's negative emotions such as fear, anger, distrust and unhappiness through a secure and warm environment and instead, activates brain functioning such as unpleasant emotions, common attention, imitation and empathy feeling in children with autism's mind and leads to their social and communicational skills development (Keino et al, 2009). Furthermore, the horse, itself, effects the social skills development in children with autism spectrum disorder. As we know, horses are social animals which are sensitive to human reactions. This kind of responding is very important for cause and effect and objective learning styles of autistic individuals. In fact, horse responds to autistic child's behavior and helps him/her to have better social understanding and become aware of his/her social and communicational behavior (Gabriels et al, 2012).

Further research on the effects of therapeutic horseback riding on cognitive and motor skills and stereotyped behaviors in children with autism spectrum disorder and social, cognitive, motor and behavioral skills of other disabled children is recommended. Generally, it is suggested to parents, specialists, teachers and trainers to utilize therapeutic horseback riding to improve the social skills of children with autism spectrum disorder.

\section{References}

All, A. C., Loving, G. L., \& Crane, L. L. (1999). Animals, horseback riding, and implications for rehabilitation therapy. Journal of Rehabilitation, 65(3), 49-57.

Bass, M. M., Duchowny. C. A., \& Llabre, M. M. (2009). The Effect of Therapeutic Horseback Riding on Social Functioning in Children with Autism. Journal of Autism and Developmental Disorders, 39, 1261-1267. http://dx.doi.org/10.1007/s10803-009-0734-3

Bellini, S, Peters, J. K., Benner, L., \& Hope, A. (2007). A meta- analysis of school - based social skills interaction for children with autism spectrum disorder. Remedial and Special Education, 28(3), 152-162. http://dx.doi.org/10.1177/07419325070280030401

Bellini, S. (2004). Social skill deficits and anxiety in high-functioning adolescents with autism spectrum disorder. $\begin{array}{lllll}\text { Focus on Autism and Developmental Disability, } & \text { 19(3), }\end{array}$ http://dx.doi.org/10.1177/10883576040190020201

Britton, V. (1991). Riding for the disabled. London: B.T. Batsford Ltd. 
Funahashi, A., \& Carterette, E. C. (1985). Musical empathy. Journal of auditory research, 25(1), 47-65.

Gabriels, R. L., Agnew, J. A., Holt, K. D., Shoffner, A., Zhaoxing, P., Ruzzano, S., Clayton, G. H., \& Mesibov, G. (2012). Pilot study measuring the effects of therapeutic horseback riding on school-age children and adolescents with autism spectrum disorders. Research in Autism spectrum disorder, 6, 578-588. http://dx.doi.org/10.1016/j.rasd.2011.09.007

Hauck, M., Fein, D., Waterhouse, L., \& Feinstein, C. (1995). Social initiations by autistic children to adults and other children. Journal of Autism and Developmental Disorders, 25(6), 579-595. http://dx.doi.org/10.1007/BF02178189

Ingersoll, B., Lewis, E., \& Kroman, E. (2007). Teaching the imitation and spontaneous use of descriptive gestures in young children with autism using a naturalistic imitation intervention. Journal of Autism and Developmental Disorders, 37, 1446-1456. http://dx.doi.org/10.1007/s10803-006-0221-z

Keino, H., Funahashi, A., Keino, H., Miva, C., Hosokava, M., Hayashi, Y., \& Kavakita, K. (2009). Horseback riding to facilitate communication ability of children with pervasive developmental disorders. Journal of Equine Science, 20(4), 79-88. http://dx.doi.org/10.1294/jes.20.79

King, N. (2007). Perceived efficacy of therapeutic riding for children with autism. In B. Engel, \& J. MacKinnon (Eds.), Enhancing human occupation through hippotherapy (pp. 119-126). Bethesda, MD: American Occupational Therapy Association.

Kuoch, H. (2000). Social story interventions for young children with autism spectrum disorders. A thesis submitted in partial fulfillment of requirements for the degree of master of arts in the university of British Columbia.

Macauley, B. L., \& Guiterrez, K. M. (2004). The effectiveness of hippo therapy for children with language-learning disabilities. Communication Disorders Quarterly, 25(4), 205-217. http://dx.doi.org/10.1177/15257401040250040501

Mash, J. E., \& Barkley, R. A. (Eds) (2006). Treatment of childhood disorders. New York: Guilford.

Scttone, D., Daniel, H., Tingstrom, \& Susan, M. Wilczynski. (2006). Increasing appropriate social interactions of children with autism spectrum disorder using social stories. Focus on autism and other development disabilities, 21(4), 211-222. http://dx.doi.org/10.1177/10883576060210040201

Sigman M. D., Kasari C., Kwon J. H., \& Yirmiya N. (1992). Responses to the negative emotions of others by autistic, mentally retarded, and normal children. Child Development, 63, 796-807. http://dx.doi.org/10.2307/1131234

Smith, T. E. C., Polloway, E. A., Patton, J. R., \& Dowdy, C. A. (2011). Teaching Students with Special Needs in Inclusive Settings. New York: Allyn \& Bacon, Inc.

Stone, W. L., Coonrod, E. E., \& Ousley, O. Y. (2000). Brief report - screening tool for autism in two-year-olds (STAT): Development and preliminary data. Journal of Autism and Developmental Disorders, 30, 607-612. http://dx.doi.org/10.1023/A:1005647629002

Stone, W., Ruble, L., Coonrod, E., Hepburn, S., Pennington, M., Burnette, C., \& Brighham, N. (2010). TRIAD Social Skill Assessment. Nashvill: Vanderbilt Kennedy Center.

\section{Copyrights}

Copyright for this article is retained by the author(s), with first publication rights granted to the journal.

This is an open-access article distributed under the terms and conditions of the Creative Commons Attribution license (http://creativecommons.org/licenses/by/3.0/). 